\title{
A perspective on the recognition of other-race faces
}

\author{
PAUL J. LAVRAKAS, JOHN R. BURI, and MARK S. MAYZNER \\ Loyola University of Chicago, Chicago, Illinois 60626
}

\begin{abstract}
The purpose of the present study is to provide a perspective on the recognition of other-race faces, i.e., black faces by white subjects. Past research has indicated that individuals have greater difficulty recognizing other-race faces than they do same-race faces. On the basis of previous findings, we chose to investigate the recognition of black faces by white subjects as a function of the quantity and quality of previous experience with blacks, racial attitudes, field dependence/independence, and recognition training. Forty-two white subjects participated in pre, post-, and delayed recognition tests. Subject data were also collected to explore individual differences in recognition performance. Using multiple regression techniques, it was found that field dependence/independence accounted for the largest proportion of variance in recognition performances; a feature-discrimination training task and past experience with blacks were also found to significantly relate to recognition performance. The applied aspects of these results are discussed.
\end{abstract}

Recognition of faces is a complex cognitive process which, for many individuals, is further complicated when the face to be recognized is of another race. Past research (e.g., Luce, 1974; Malpass \& Kravitz, 1969) has demonstrated that when white subjects are shown both black and white faces, they are subsequently less able to recognize the black faces than they are the white faces. The purpose of the present study is the investigation of several variables which appear to be related to white individuals' recognition of black faces. This will be referred to as "other-race recognition", although the symmetrical case of recognition of white faces by black subjects was not studied. In addition, since there is no parallel samerace recognition, this work alone does not differentiate between factors specific to other-race and to same-race recognition.

Several variables have been suggested to be related to a person's ability to recognize an other-race face; the most frequently entertained of these is experience. The experience hypothesis suggests that a person's relative difficiency in recognizing other-race faces stems from a lack of personal experience with otherrace individuals. This is an intuitively sound suggestion since the bulk of the populace still lives in racially homogeneous areas. In investigating this experience-hypothesis, Malpass and Kravitz (1969) and Luce (1974) administered questionnaires to their subjects in an effort to determine the extent of their

The order of the first two authors' names is fortuitous. This research was supported, in part, by Grant NSF-GS-35280 from the National Science Foundation awarded to Leonard Bickman. The authors thank Emil J. Posavac and Leonard Bickman for their helpful comments on an earlier version of this paper, which was presented at the 1975 American Psychological Association convention. previous exposure to members of other races. Contrary to expectation, this measure of experience was not found to be related to recognition of other races. Similarly, Cross, Cross, and Daly (1971) found that whether a person lived in a racially segregated or a racially integrated neighborhood was not related to recognition of other races. These findings, derived from investigations of the quantity of exposure to other races, suggest that quantity may not be the best measure of experience as it relates to other-race recognition, i.e., the quality of that experience may be a more important determinant of recognition. Therefore, white subjects in the present study provided information concerning both the quantity and the quality of their past experience with blacks.

Other researchers (e.g., Galper, 1973; Seeleman, 1940) have suggested that it is one's attitudes towards other-race individuals which act as an important correlate of other-race recognition. In each of these studies, it was found that white subjects who held positive attitudes towards blacks displayed significantly better recognition of black faces than did white subjects with less positive attitudes towards blacks. In the present study, a modified version of the Sedlacek and Brooks' (1970) racial attitudes scale was administered to white subjects in order to assess their attitudes towards blacks.

Past research has also indicated that a person's field dependence/independence is related to his/her recognition of faces. Witkin, Dyk, Faterson, Goodenough, and Karp (1974) reported that fielddependent individuals were better able than fieldindependent ones to recognize same-race people with whom they had interacted briefly. Similarly, Messick and Damarin (1964) found that field-dependent persons were superior to field-independent ones in 
the recognition of pictures of same-race faces. It was suggested that these findings were the result of the characteristic orientation of a field-dependent person to structure ambiguous situations by relying upon external social referents, especially external referents that are seen as a good source of information for reducing this ambiguity. Such an orientation likely results in a greater attention to the cues provided by a same-race individual, especially facial cues which convey that person's thoughts and feelings. In the case of an other-race individual, however, it might be expected that this relationship does not hold since persons of one race may not view persons of another race as reliable sources of information. In this latter situation, facial recognition may simply be a form of pattern recognition (Hake, Note 1). To the extent that this is the case, it may be suggested that field-independent subjects will perform better in an other-race facial recognition task. This follows from the parallel between the recognition task, i.e., viewing a face and then later recognizing it among a set of other faces, and the field dependence/independence task, i.e., seeing a figure and then identifying it as part of a more detailed drawing. In the present study, the Concealed Figures Test (Thurstone \& Jeffrey, 1965) was administered to the subjects in order to assess the relationship of field dependence/independence to facial recognition of other races. ${ }^{1}$

Attempts to improve white subjects' recognition of other-race faces through training have also been undertaken. Malpass, Lavigueur, and Weldon (1973) found that a verbal training task in which subjects were required to describe characteristics of otherrace faces failed to aid recognition performance, even after $8 \mathrm{~h}$ of distributive training. In a second experiment, these researchers found that a visual four-alternative forced-choice shock-avoidance training procedure did facilitate white subjects in their recognition of black faces after $1 \mathrm{~h}$ of training. Elliott, Wills, and Goldstein (1973) reported that the recognition of oriental faces by white subjects was aided by a visual paired-associate training task. These results indicate that visual training can be helpful in raising the immediate performance of subjects in recognizing other-race faces; however, it is uncertain from these studies whether any lasting effects were derived from the training procedures. In pattern-recognition research, Hull (1920) has demonstrated that requiring subjects to make fine discriminations among novel and similar stimuli improved their ability to later differentiate these stimuli. Following from this result, a training procedure employed in the present study required white subjects to make fine discriminations of specific features (e.g., lips, nose, eyes, etc.) of black faces which were constructed with an Identi-Kit. ${ }^{2}$
In review, the present study investigates the recognition of black faces by white subjects as a function of quantity of experience, quality of experience, attitudes towards blacks, field dependence/ independence, and a feature-discrimination training task. Specifically, the following were hypothesized for white subjects: (1) Past experience with blacks, especially the quality of that experience, is positively related to recognition performance. (2) A positive attitude towards blacks is positively related to the recognition of black faces. (3) Field independence is positively related to recognition of black faces. (4) Subjects receiving the feature-discrimination training will perform better than the control group; the influence of the passage of time upon the effect of training is also investigated. This multifaceted approach has been taken in order to provide a needed perspective on the relationships among several variables which have been found to be related to otherrace recognition.

\section{METHOD}

\section{Subjects}

Participants were 21 female and 21 male white undergraduates. Equal numbers of both sexes were randomly assigned to three groups: a simple concept-learning group; a conjunctive conceptlearning group; and a control group. In addition, six black subjects particiated in a separate black control condition. Subjects ranged in age from 18 to 23 years and were predominantly from an urban background.

\section{General Procedure}

One of two male experimenters supervised the subjects' participation in two experimental sessions. The subjects participated individually in the following manner: (a) The first session began with the subjects' completing a modified version of the Sedlacek and Brooks' (1970) Racial Attitudes Scale. ${ }^{3}$ (b) Next, a facial recognition pretest was administered to the subject. (c) The subject then participated in either a simple concept-learning training task, a conjunctive concept-learning training task, or a control task. (d) Following a 2-min rest, a facial recognition posttest was administered, and Session 1 ended. (e) Session 2 began 1 week later with a facial recognition delay test. (f) Next, the Concealed Figures Test was administered to the subject. (g) Finally, the subject was asked to complete an experiencebackground questionnaire.

\section{Subject Variables}

White subjects were asked to respond to several questionnaire items concerning the extent of their previous familiarity with blacks (i.e., quantitative experience) and their present number of black friends (i.e., qualitative experience). In addition, each white subject was given a version of the Sedlacek and Brooks' (1970) Racial Attitudes Scale, which was modified to conform with the time constraints of our experimental sessions. A high score on this scale indicates negative attitudes towards blacks. Each subject also responded to the Concealed Figures Test (Thurstone \& Jeffrey, 1965), thus providing a measure of field dependence/independence. This test has a split-half reliability of .94 .

\section{Recognition Stimuli and Recognition Task}

Stimuli for the recognition tests were constructed from high school yearbook pictures of 324 black males. Fifty-four randomly 
selected pictures were designated as targets. These targets were photographed individually as 35-mm slides; each target was then randomly positioned among five other randomly selected pictures in a 2 by 3 matrix. (Each face in a matrix was associated with a number from 1 to 6 for purposes of later identification.) The resulting 54 matrices (i.e., one target and five nontargets) were also photographed as $35-\mathrm{mm}$ slides. All faces were displayed so as to eliminate the presence of clothing.

Each target slide and its appropriate group slide were then assigned to one of three stimuli sets; each set consisted of 18 target slides and the 18 corresponding group slides. The 36 slides within a set were then arranged in a slide tray in the following order: 3 target slides, 3 corresponding group slides, 1 blank slide, 3 target slides, 3 group slides, 1 blank slide, etc.

The three sets of slides were used in the recognition tests. Each subject viewed a different set for the pretest, posttest, and delay test. The order of slide-set presentation was counterbalanced, and the subjects were randomly assigned a viewing order. A slide-projector programmer displayed each target slide for $1.5 \mathrm{sec}$, each group slide for $6.5 \mathrm{sec}$, and each blank slide for $1.5 \mathrm{sec}$, with an interslide interval of $0.5 \mathrm{sec}$. In the recognition tests, a subject was required to first view three target slides and then the three corresponding group slides. The subject was instructed to verbally identify the correct target in each group slide within the $6.5 \mathrm{sec}$. This procedure was continued for the entire stimulus set. Extensive pretesting indicated that this recognitiontest protocol provided white subjects with a difficult, yet not impossible, task.

\section{Training Stimuli and Training Task}

An Identi-Kit was used to construct the stimuli for the conceptlearning training tasks. Male faces with primarily black features were constructed from foils representing chin, lips, nose, eyes, eyebrows, ears, and hair. By systematically varying the head shape (large, medium, small), hair style (long, medium, short), eyes (dark, light), and lips (thick, thin), 36 faces were constructed and photographed as $35-\mathrm{mm}$ slides. Of these 36 slides, 27 were chosen to serve as stimuli in the concept-learning tasks. The simple concept was represented by light eyes, which appeared in 9 of the 27 Identi-Kit faces. The conjunctive concept was represented by dark eyes and thick lips, which appeared together in 9 of the Identi-Kit slides.

A subject assigned to the simple concept-learning training condition yiewed the Identi-Kit slides for $10 \mathrm{sec}$ each, during which time the subject responded "concept" or "no concept" to each slide and the experimenter informed the subject as to whether his/her response was "correct" or "incorrect." After the subject met the criterion of five correct responses in a row, he/she was asked what the concept was. The number of slides required by the simple-condition subjects to obtain the concept ranged from 7 to 63.

Each subject in the conjunctive concept-learning training condition was randomly yoked to a subject who had previously participated in the simple training condition; in this way, there was a subject in the conjunctive condition who saw the same number of training slides as one of the subjects in the simple condition. The conjunctive training methodology was otherwise identical to the simple-condition methodology.

The white control subjects were instructed to rate the Identi-Kit faces for attractiveness on a 7-point scale. This was done in order to expose them to the training stimuli. ${ }^{3}$ They were unaware that other subjects received a training task using these same stimuli.

\section{RESULTS}

\section{Group Differences on Recognition Tests}

A score for each subject on each of the three recognition tests was computed by determining his/her number of correct responses; this score could
Table I

Group Means and SDs for Recognition Scores at Pre-, Post-, and Delay-Test Stages

\begin{tabular}{|c|c|c|c|c|c|c|}
\hline \multirow[b]{2}{*}{ Condition } & \multicolumn{2}{|c|}{ Pretest } & \multicolumn{2}{|c|}{ Posttest } & \multicolumn{2}{|c|}{ Delay-Test } \\
\hline & Mean & SD & Mean & $\mathrm{SD}$ & Mean & SD \\
\hline Control & 10.36 & 2.40 & 10.29 & 2.81 & 11.07 & 2.73 \\
\hline Simple & 10.14 & 3.46 & 11.71 & 2.54 & 10.86 & 2.34 \\
\hline Conjunctive & 10.00 & 2.69 & 11.93 & 2.49 & 11.07 & 2.50 \\
\hline
\end{tabular}

range from 0 to 18 on each of the recognition tests. The group means and standard deviations for the three recognition tests are presented in Table 1. These mean group differences are also illustrated in Figure 1. As would be expected from randomization, the groups were equivalent on the recognition pretest. Also, following the hypothesized expectation, an a priori comparison (Winer, 1971, p. 269) indicated that the two training groups performed significantly better than the control group on the recognition posttest $[F(1,72)=5.64, p<.05]$. After a 1 -week delay, all groups were equivalent on the recognition delay test; however, they did show a marginal improvement over their pretest performance $[t(41)=$ $1.96, \mathrm{p}<.10$ ]. Figure 1 illustrates this marginal improvement over time. Figure 1 also illustrates that the white subjects were inferior to the black subjects in pretest recognition, supporting previous findings $[\mathrm{t}(46)=1.96, \mathrm{p}<.05]$.

\section{Multiple Regression Anglysis}

The major focus of this study is to provide a perspective of the interrelationships among the variables

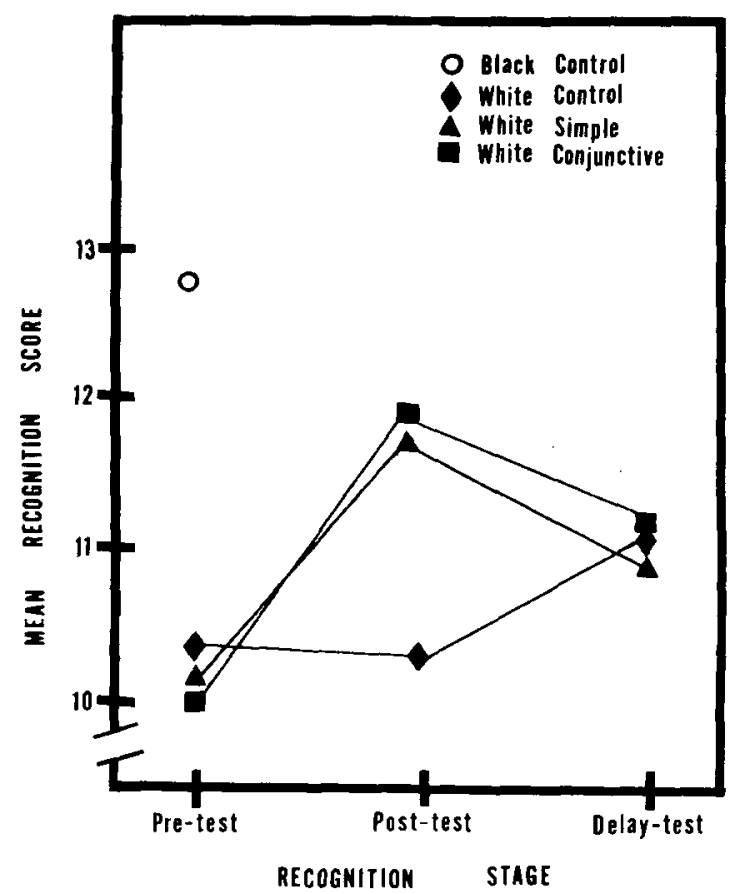

Figure 1. Recognition performance at pre-, post-, and delaytest stages. 
that past research has shown to be related to otherrace recognition. Therefore, a multiple regression approach was deemed most appropriate since it enables a direct comparison of the importance of the of the independent variables in predicting other-race recognition.

In the analyses, the Experience factor is represented by two vectors ${ }^{6}$ : a vector referring to the quantity of experience with blacks $(1=$ nonintegrated elementary and high school, 2 = integrated elementary and/or high school), and a vector representing the quality of experience (the actual number of close black friends). One-third of the subjects attended integrated schools, and one-fifth of the subjects reported that of their five closest friends, at least one was black. The Attitudes factor is represented by a vector of raw scores on the modified Sedlacek and Brooks Racial Attitudes Scale. The Field Dependence/Independence factor is represented by a vector of raw scores on the Concealed Figures Test. The mean subject score was 74.33, with a standard deviation of 26.27 . Finally, the Training factor is represented by a vector coded for the a priori comparison of the subjects receiving the feature-discrimination training vs. the control subjects.

Recognition pretest. The various intercorrelations among the variables at the pretest stage are displayed in Table 2a. Significant intercorrelations were found among field dependence/independence, quantity of experience, and recognition performance.

Table 3a shows the results of the multiple regression analyses at the pretest stage. Inspection of Table 3a allows for a direct comparison of the variables which provide the best predictions of recognition performance. In this table, standardized regression coefficients are presented for each variable which entered an equation. The $\mathrm{R}^{2}$ associated with Equation I indicates that subjects' prior experience with blacks is significantly related to their recognition performance $[\mathrm{F}(2,39)=4.22, \mathrm{p}<.05]$. But inspection of the individual beta weights shows an unexpected result: while the number of close black friends a subject has is positively related to his/her recognition score, subjects who went to more integrated schools displayed poorer recognition performance. These results suggest that the effect of experience on the recognition of other-race faces is a complex one, and that prior attempts at measuring it as a single variable may not have been sufficiently sensitive. Equation II accounts for no appreciable variance in recognition scores $\left(R^{2}=.012\right)$, and, as such, does not support previous findings that suggest that attitudes towards blacks is related to recognition of black faces by whites. Equation III shows that field dependence/ independence is the single most important variable in predicting a subject's pretest recognition score $[F(1,40)=13.95, p<.001]$; i.e., field-independent persons perform significantly better than fielddependent ones in other-race recognition. Of the remaining equations in Table $3 \mathrm{a}$, it is important to note Equation V. This equation, which includes both field dependence/independence and the experiential variables, is the best equation for predicting pretest recognition. The $\mathrm{R}^{2}$ for this equation is .39 ; this is a significantly larger value than the amount of variance accounted for by Equation III $[F(2,38)=4.70$, $\mathrm{p}<.05]$. This implies that for the pretest, field independence and experience provide the best, and most parsimonious, prediction of performance.

Recognition posttest. The results relating to

Table 2

Intercorrelations at Pre-, Post-, and Delay-Test Stages

\begin{tabular}{|c|c|c|c|c|c|}
\hline & $\begin{array}{c}\text { Quantity of } \\
\text { Experience }\end{array}$ & $\begin{array}{l}\text { Quality of } \\
\text { Experience }\end{array}$ & $\begin{array}{c}\text { Racial } \\
\text { Attitudes }\end{array}$ & $\begin{array}{l}\text { Field Dependence/ } \\
\text { Independence }\end{array}$ & Training \\
\hline & \multicolumn{5}{|c|}{ 2a-Intercorrelations at Pretest Stage } \\
\hline \multirow[t]{2}{*}{$\begin{array}{l}\text { Recognition Score } \\
\text { Quantity of Experience } \\
\text { Quality of Experience } \\
\text { Racial Attitudes }\end{array}$} & $-.359^{*}$ & $\begin{array}{l}.143 \\
.205\end{array}$ & $\begin{array}{l}-.107 \\
-.081 \\
-.229\end{array}$ & $\begin{array}{l}.508^{* *} \\
-.322^{*} \\
-.221 \\
-.057\end{array}$ & \\
\hline & \multicolumn{5}{|c|}{$2 \mathrm{~b}-$ Intercorrelations at Posttest Stage } \\
\hline $\begin{array}{l}\text { Recognition Score } \\
\text { Quantity of Experience } \\
\text { Quality of Experience } \\
\text { Racial Attitudes } \\
\text { Field Dependence/Independence }\end{array}$ & -.246 & $\begin{array}{r}-.075 \\
.205\end{array}$ & $\begin{array}{l}-.195 \\
-.081 \\
-.229\end{array}$ & $\begin{array}{r}.346^{*} \\
-.322^{*} \\
-.221 \\
-.057\end{array}$ & $\begin{array}{r}.266^{*} \\
-.073 \\
-.281 \\
-.046 \\
.015\end{array}$ \\
\hline Field Dependence/Independence & \multicolumn{5}{|c|}{ 2c-Intercorrelations at Delay-Test Stage } \\
\hline $\begin{array}{l}\text { Recognition Score } \\
\text { Quantity of Experience } \\
\text { Quality of Experience } \\
\text { Racial Attitudes } \\
\text { Field Dependence/Independence }\end{array}$ & -.203 & $\begin{array}{l}.019 \\
.205\end{array}$ & $\begin{array}{l}-.169 \\
-.081 \\
-.229\end{array}$ & $\begin{array}{l}.516^{* *} \\
-.322^{*} \\
-.221 \\
-.057\end{array}$ & $\begin{array}{r}-.019 \\
-.073 \\
-.281 \\
-.046 \\
.015\end{array}$ \\
\hline
\end{tabular}

Note $-N=42$ 
Table 3

Regression Equations at Pre-, Post-, and Delay-Test Stages for the Prediction of Recognition Performance

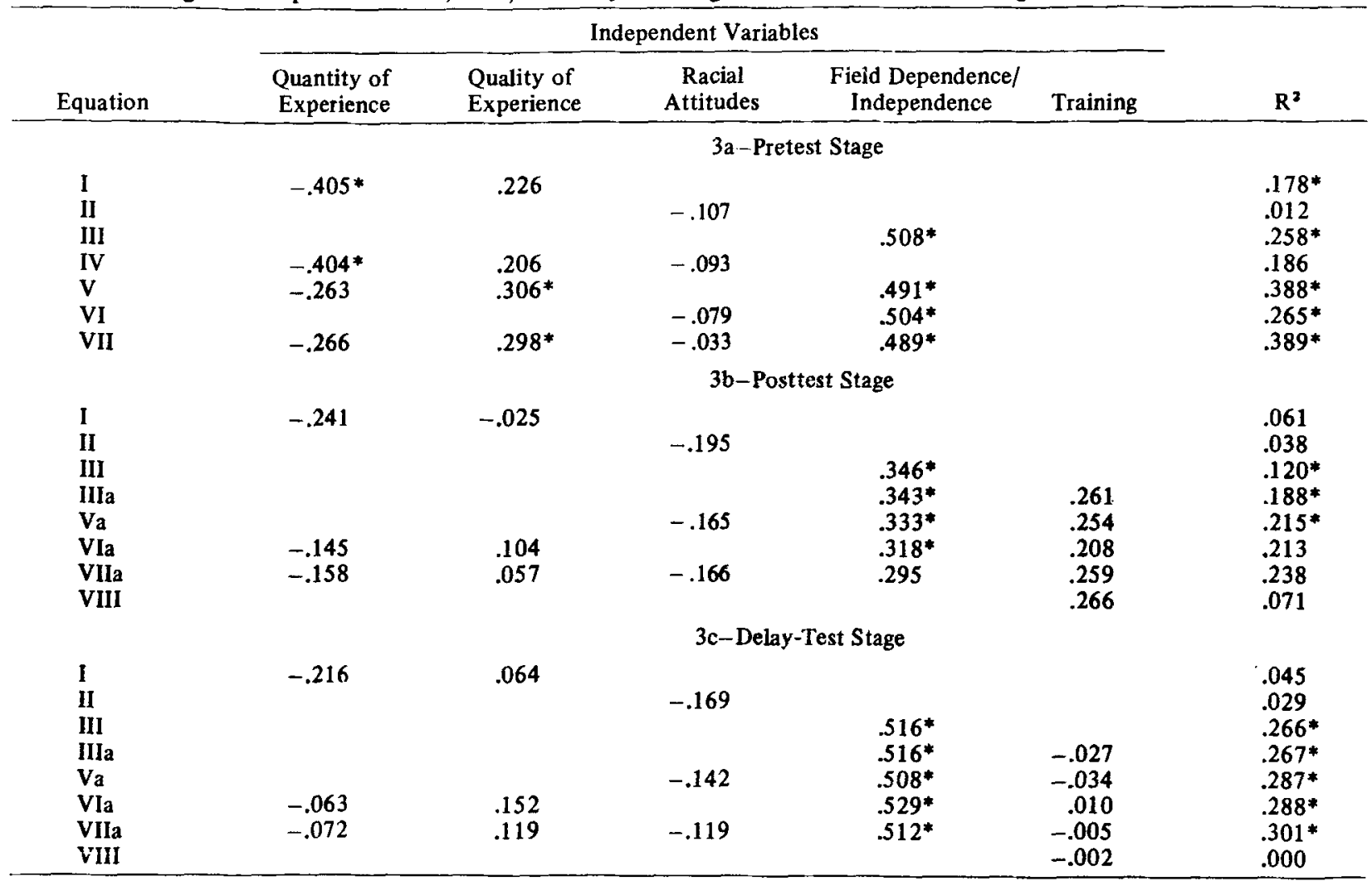

Note $-N=42$; dependent variable in all equations is recognition score; all regression coefficients are in standardized form $* p<.05$

recognition performance on the posttest are shown in Tables $2 b$ and $3 b$. The $R^{2} s$ associated with Equations $I$ and II in Table $3 b$ show that experience and attitudes are unrelated to recognition performance. Field dependence/independence (Equation III), on the other hand, is still significantly related to recognition at this stage $[F(1,40)=5.45, p<.05]$. However, a comparison of the size of the beta weights and the $R^{2} s$ for the Equations III in Tables $3 a$ and $3 b$ shows that field dependence/independence is less important at the posttest than it was at the pretest. It is of interest to note, in Table $2 b$, the virtual nonrelationship between training and the field dependence/independence $[\mathrm{r}(40)=.015]$. This suggests that an equation incorporating these two important, yet independent, variables may be a better predictor than Equation III. Equation IIIa, which represents training and field dependence/independence, accounts for more variance than Equation III $[F(1,39)=3.24, p<.08]$. While this difference in $R^{2} s$ is marginally significant, its size (.068) is fairly small. We interpret this to be consistent with the limited intensity of the training; had the training task been more intense, its effect may have been more pronounced.
None of the other equations in Table $3 b$ are superior to Equation IIIa. It is of interest to note that prior experience with blacks now takes a relatively minor role in prediction of recognition performance, as indicated by the small beta weights for the experience variables in Equation Va.

Recognition delay test. As shown in Table 2c, field dependence/independence appears most strongly related to delay-test recognition $[\mathrm{r}(40)=.516$, $p<.001]$. The results in Table $3 c$ show that the importance of field dependence/independence dominates all the equations it enters. Equation III is therefore the most accurate predictor, with an $\mathbf{R}^{2}$ value that is both highly significant $[\mathrm{F}(1,40)=14.50$, $\mathrm{p}<.001]$ and of sizable magnitude, i.e., simply knowing a subject's perceptual orientation accounts for $27 \%$ of the recognition score variance.

\section{DISCUSSION}

As previously stated, the general purpose of this research was an attempt to provide a perspective on several variables that have previously been shown to relate to the recognition of black faces by white subjects: experience with blacks, attitudes towards 
blacks, field dependence/independence, and training. Although it is logical that one's experience with another race should relate to recognition of that race, the present findings indicate that experience is a complex factor. If experience is related to other-race recognition, it appears to be the quality of that experience that is most important. Being white and actually having black friends was found to be more positively related to recognition of black faces than merely having grown up in an integrated neighborhood or having gone to school with blacks.

Concerning the attitudes-towards-blacks variable, the paper-and-pencil measure used in this study was found to be unrelated to recognition performance, which is contrary to previous findings. However, having black friends, which implies a nonnegative attitude towards blacks, is a variable which relates positively to recognizing black faces. These results suggest that, while attitudes towards blacks may be an important factor in the recognition of black faces, the questionnaire employed here was not sufficiently sensitive to detect these effects.

From an individual differences perspective, the most important finding here is that although whites as a group do more poorly than blacks in recognizing black faces, not all whites do equally poorly. Contrary to what other research findings (Messick \& Damarin, 1964; Witkin et al., 1974) might imply, it was found that field-independent white subjects are superior to field-dependent white subjects in the recognition of black faces (as operationalized in the present study). These findings may be of special interest to urban police forces, for whom the use of the Concealed Figures Test might be beneficial as a personnel screening tool. The implication here is that a field-independent white policeman working in a black community may have an advantage in performing patrol duties over his field-dependent counterpart who works in the same community but who may be more likely to feel that "they all look alike to me."

Of special interest from an applied perspective is the finding that training significantly improved immediate recognition performances. While the feature-discrimination training task employed in this study is less intensive than those training tasks used previously (i.e., Elliott et al., 1973; Malpass et al., 1973), it appears to be as efficient, and more salient. One possible reason for the effectiveness of this training may be that white subjects find it difficult to recognize black faces because they code the black face simply by its blackness (cf. Malpass, Note 2). If this is the case, then training people to focus on more specific features in a face (e.g., eyes, lips, etc.) may serve to eliminate at least part of the deleterious effect of remembering only skin color. The subsequent posttest recognition performances indicated that this feature-discrimination training had a positive effect. Let it be clearly stated, however, that we do not view these results as an indication that this training technique is an instant answer to improving whites' recognition of black faces. While other researchers who employed successful training techniques reported only immediate posttest results, our subjects returned a week later in order to determine whether our training had a lasting effect. At the delay test, our three groups showed no differences. This null result is not surprising when one considers the low intensity of our training and our lack of control over our subjects' histories during the week delay. We do feel, however, that a more extensive featurediscrimination task (e.g., one on the order of training used by the military to develop individuals' ability to recognize various shapes) would have a greater and more lasting positive effect on other-race recognition.

\section{REFERENCE NOTES}

1. Hake, H. Discussant in J. Chance (Chair), Faces: How do we perceive and remember them? Symposium presented at the meeting of the Midwestern Psychological Association, Chicago, 1975.

2. Malpass, R. S. Toward a theoretical basis for understanding differential face recognition. In J. Chance (Chair), Faces: How do we perceive and remember them? Symposium presented at the meeting of the Midwestern Psychological Association, Chicago, 1975.

3. Witkin, H. A., Cox, P. W., Friedman, F., Hrishikesan, A. G., \& Siegel, K. N. Research Bulletin 74-42. Princeton, New Jersey: Educational Testing Service, 1974.

\section{REFERENCES}

Cross, J. F., Cross, J., \& Daly, J. Sex, race, age, and beauty as factors in recognition of faces. Perception \& Psychophysics, $1971,10,393-396$.

Elliott, E. S., Wills, E. J., \& Goldstein, A. G. The effects of discrimination training on the recognition of white and oriental faces. Psychonomic Society Bulletin, 1973, 2, 71-73.

GALPER, R. E. "Functional race membership" and recognition of faces. Perceptual and Motor Skills, 1973, 37, 445-462.

Hull, C. L. Quantitative aspects of the evolution of concepts. Psychological Monograph, 1920, 28(Whole No. 123).

Kerlinger, F. N., \& Pedhazer, E. J. Multiple regression in behavioral research. New York: Holt, Rinehart, \& Winston, 1973.

LuCE, T. S. Blacks, whites, and yellows: They all look alike to me. Psychology Today, 1974, 8, 105-108.

Malpass, R. S., \& KRAVITZ, J. Recognition for faces of own and other race. Journal of Personality and Social Psychology, 1969, 13, 330-334.

Malpass, R. S., Lavigueur, H., \& Weldon, D. E. Verbal and visual training in face recognition. Perception \& Psychophysics, 1973, 14, 285-292.

Messick, S., \& Damarin, F. Cognitive styles and memory for faces. Journal of Abnormal and Social Psychology, 1964, 69, 313-318.

Sedlacek, W. E., \& Brooks, G. C., JR. Measuring racial attitudes in a situational context. Psychological Reports, 1970, 27. 971-980.

SEELEMAN, V. The influence of attitude upon the remembering of pictorial material. Archives of Psychology, 1940, 36, No. 258.

Thurstone, L. L., \& JefFrey, T. E. Closure flexibility test. University of Chicago Press, Chicago, 1965. 
WINER, B. J. Statistical principles in experimental design (2nd ed.). New York: McGraw-Hill, 1971.

Witkin, H. A., Dyk, R. B., Faterson, H. F., Goodenough, D. R., \& KARP, S. A. Psychological differentiation. Potomac, Md: Erlbaum, 1974.

\section{NOTES}

1. This inventory was chosen to measure field dependence/ independence because it is easily administered and is considered a valid measure of the construct (Witkin, Cox, Friedman, Hrishikensan, \& Siegel, Note 3, p. 3).

2. Identi-Kit Company, 3700 Newport Boulevard, Newport Beach, California 92660. The authors thank Officer Chris Johnson of the Evanston Police Department for his assistance in the use of the Identi-Kit.

3. Black subjects were not administered this questionnaire.

4. Twelve of the 14 subjects in the conjunctive condition obtained the concept within the number of slides permitted.

5. The authors thank Joseph F. King for this procedural suggestion.

6. See Kerlinger and Pedhazur (1973) for an explanation of vector generation.

(Received June 24, 1976;

revision received September 16, 1976.) 